\title{
Artificial Intelligence and Children's Education: Review Study
}

\author{
AlJohara Bint Fahad AalSaud ${ }^{1}$ \\ ${ }^{1}$ Education College, King Saud University, Riyadh, Saudi Arabia \\ Correspondence: AlJohara Bint Fahad AalSaud, Associated Professor, Education College, King Saud University, \\ Riyadh, Saudi Arabia.
}

Received: June 2, 2021

Accepted: June 20, 2021

Online Published: June 30, 2021

doi:10.5430/irhe.v6n2p1

URL: https://doi.org/10.5430/irhe.v6n2p1

\begin{abstract}
Literature review is an important part within the content of any scientific study. It fulfills many purposes and objectives, including that it gives the researcher ideas about the most important variables that the previous studies have proven their importance or lack of importance in a specific field or ideological and cognitive direction. This study came with the aim of compiling the latest Arab and foreign theoretical studies, highlighting the process that researched the subject of artificial intelligence AI and the education of children, classifying, analyzing and commenting on their results in order to help students and researchers in the educational field to use it as a tool in their research. The current review study will help the researcher to see previous studies and to identify points of similarities and differences between the results of these studies, as well as giving an impression about the relationship between the studied variables, providing the researcher with information about the science that has been accomplished and which can be conducted and applied, and the necessary research topics. Further research and study are recommended in it to enrich the topics of artificial intelligence AI and the education of children, especially during the current period of transition to blended learning and online educational systems.
\end{abstract}

Keywords: artificial intelligence, children education, study, learning

\section{Introduction \& Background}

As a result of technological development and the tremendous knowledge revolution the twenty-first century have witnessed, educational institutions in all stages of public and higher education have turned to search for the best educational and technological means to make optimum use of technologies and provide opportunities for the best educational outcomes that contribute to the desired academic progress and thus has led to effective people in their societies.

Many educators emphasize the need for expansion and comprehensive knowledge in the use of educational technologies because they have become an integral part of the educational process and the necessity to keep up with what is new of these technologies and circulate them to schools and to pay attention to training on these technologies according to future educational technology (Al-Helah, 2014).

The scientific and technical development has also led to the obligation of educational institutions to use modern means of education and implement technology of various kinds that increase teachers' experience by developing their performance to meet the challenges of the day, training on modern technological programs and keeping pace with development and employing them in a way that serves the learner and some these programs depend on artificial intelligence.

(Nuland \& Rogers) pointed to the great role of computer technologies in developing and improving the educational process by using programs and applications on a large scale to reach distinct educational results in different educational conditions that seek the learner's fast and easy access to information.

Artificial intelligence had begun as a scientific breakthrough during the previous years with superior skills and achievements in all different areas of life, such as industry, medicine, education and economics, and it also had a role in security systems in the field of image analysis and voice recognition, as well as in the field of language processing and stock exchange (Qamoura, 2018).

Artificial intelligence has become an integral part of our everyday life, starting with simple computers, then it developed into smart phones, advanced computers and robots, so the entry of artificial intelligence into the areas of life 
had the biggest role in progress and prosperity, as it was not confined to the scientific and technological fields, but rather reached the field of human sciences and social science, because it is product of a group of sciences such as behavioral science, neurotransmitters, and computer science, as it is a science that includes algorithms as well as theoretical and applied sciences. it has become a science that has the ability to contribute to decision-making, either partially or completely through adaptation, quotation and prediction (Zorkouki, 2020).

Artificial intelligence is one of the fields of computer that focuses on systems and programs development that help solve problems and accomplish tasks distinctively while the fulfillment of those tasks by humans is considered a type of artificial intelligence that leads to the artificial development of smart tools to solve problems, increasing the efficiency of education and making it more effective. Hence, everyone realizes the importance of artificial intelligence for all parties to the educational process (teacher, student, and educational system).

The education process begins from the childhood stage, which is an important educational stage, because the interest in childhood is an interest in the future where the prosperity of nations and the progress of countries depends on this process, so there must be a strong basis for the development of countries. Early attention to this stage is necessary to meet the societal and technological challenges that will face the learner. Children, therefore should receive the best education that stimulates their energy and creative abilities that develop all aspects and life and technological skills and be able to keep pace with development and the knowledge and technical expansion, so students have the right to obtain the best types of education that develop their intelligence through technical programs and computers (Al-Shuraida, 2020).

Educators have showed interest in the childhood education stage because it is the first educational stage upon which children's subsequent learning is based, attitudes and tendency towards the education process are identified and basic skills are built, so they must be learnt by teachers with cognitive qualifications who provide the best education in which modern strategies and technical programs are implemented and engage students in the educational process (Katame, 2018).

Artificial intelligence contributes to the development of educational systems that, in turn, contribute to improve the educational process in all its aspects through the development of smart tools and programs artificially to solve many problems and enrich educational activities that help to acquire experiences and skills. With the tremendous technological advancements, the use of artificial intelligence has become imperative as an integral part of teaching process.

Some educators have conducted studies about the future of education in the coming few years. Among them (Mu, 2019) who indicated that traditional education will cease to exist and will be replaced by artificial intelligence which is going to be within.

The education system with the teacher in all educational institutions, and at present time the role of artificial intelligence has begun to emerge clearly and effectively because there are some tasks that the human mind does not perform. In its existence, education has become more flexible. This having been said, the role of the teacher is indispensable and artificial intelligence will not be a guide to solve learners' psychological and social problems, yet the teacher is no longer the source of information after this technological development.

Artificial Intelligence, with all its systems and programs, aims to provide electronic support to students during learning process, helps them solve the problems they face, adapts education to the learner's needs, provide feedback that helps them improve their learning, facilitates the process of deduction and prediction and is based on the science of algorithms which made artificial intelligence an effective element in the field of algebra, geometry and other sciences. Artificial Intelligence also helps overcome some difficulties and explain some phenomena, and its programs came as a substitute for these challenges that traditional education could not solve (Abdul-Jawad, 2019).

\section{The Importance of the Study}

The previous studies are one of the most important scientific foundations upon which the study is based. After choosing the problem of the study, the researcher begins with research, scrutiny and analysis in the previous studies. This is because the searches are cumulative, successive processes that depend on what the predecessors presented, and from it the successors start to complete what started by those who preceded them, so the study begins with ideas and concepts related to each other through hypotheses expected to have relationships between them, and the existence or non-existence of these relationships is inferred from During a certain methodology, it depends on gathering information and referring to the educational literature and previous studies.

Therefore, previous studies are an important part within the content of the study, which fulfills many purposes and objectives, including that it gives the researcher ideas about the most important variables that the studies have proven 
their importance or lack of importance in a specific field or ideological and cognitive direction, and previous studies give the researcher the basis on which the problem is based and its importance, And then providing the opportunity to compare the current study with previous studies, and therefore the process of collecting previous studies is an assessment of what researchers have done in terms of writing issues based on objectives and problems. Therefore, reviewing this literature gives us an idea of what they have done and what they have reached.

Because of the importance of the presence of previous studies within the content of the current study, therefore, the researcher must follow a set of rules and matters that ensure that he will use previous studies to properly support his study, and among these rules is to organize the information that he collected about the previous studies, and for the researcher to carry out an installation process. The results are synthesize result so that the researcher clarifies what he has known and what he has not yet known, and that he distinguishes and knows different and multiple ideas and points of view, and develops questions for subsequent studies, and from these matters we conclude that reviewing educational literature is an organized process of classifying and analyzing information, and this information Which is supposed to be related to the study problem, and include documents that the researcher should study, journals, research and books. In conclusion, the researcher has to pay great attention to the preparation, collection and analysis of previous studies part because it leads him to reach a group of matters that he inquires and searches for, and also that it adds scientific and literary value to his study.

\section{Theoretical Framework}

\subsection{Artificial Intelligence Definition}

Artificial intelligence is one of computer sciences as it is programs and systems seeking to understand the nature of human intelligence, and this science seeks to develop its systems to work efficiently like an expert's mind and has the ability to the motor and mental processes of the human being such as simulation, deduction and smart reactions in order to play the role of the human mind.

Makkawi (2018) defined artificial intelligence as a science that make it possible for machines to think like a human mind in that a computer has a mind and has characteristics that make it simulate human mental capabilities such as the ability for deduction, reactions, analysis and other mental processes.

Artificial intelligence is a set of methods in programming computer systems that make these programs simulate human intelligence and perform some intellectual operations such as facts and rules conclusions and representing them in computer memory. Building computer machines plays a role that requires some kind of intelligence and mental capabilities when performed by a person, as these programs performs some mental functions and abilities in a specific way (Hassan, 2019).

Among those interested in the science of artificial intelligence (John McCarthy), who defined it as the science of creation intelligent machines for computer programs capable of thinking in a way that resembles threat of the human mind and learn these programs as the human mind learns and also decide and act like it, it is the science of machine simulation of human behavior. (Naseeb, 2020)

\subsection{Characteristics of Artificial Intelligence}

Ehab (2018) mentioned that artificial intelligence is a group of computer programs and systems that seek to perform mental operations that are carried out more accurately and faster than the human mind.

1- The ability to learn: that is, artificial intelligence has the ability to acquire information and set specific rules for it and classify it accurately.

2- The possibility of collecting and analyzing data into information and creating a relationship between them and this helps a wide spread of information.

3- It helps in decision-making based on the process of information analysis, as it is not just algorithms that achieve a specific goal, but can give indicators that help in decision - making.

4- Has the ability to solve problems within organizations because it relies on objective judgment and accurate solutions and provides clear information that helps officials by providing multiple solutions to problems difficult to analyze with the human mind within a short period.

5- Artificial intelligence has the ability to shorten the time and effort, so the word intelligence refers to the capabilities that a person has. The artificial programs and systems have programming that helps to carry out some tasks with faster and more accurate capabilities. 
6- Artificial intelligence has relative stability because it studies man's logical thinking processes and tries to implement that through mathematical operations, this means that it isn't not exposed to forget fullness or external influences. Therefore, the stability is relative.

All these characteristics help the student to use artificial intelligence to facilitate the learning process. In addition, these ideas will help to obtain information more accurately and with less effort, and thus improve the entire education process.

\subsection{The Roles of Artificial Intelligence}

Artificial intelligence has great and multiple roles, and here we will mention some examples of these roles as educational roles.

1. Artificial intelligence provides assistance and support to the education process, facilitates and simplifies educational and administrative work, and is considered a tremendous achievement in organizing files and facilitating the reference process, as well as organizing all areas of learning and achieving the highest levels of quality (Turbot, 2017).

2. It analyzes and interprets data, no matter how large it is, that it is difficult for the teacher to do and analyze, for example, in multiple-choice questions. Artificial intelligence systems analyses students' reactions more deeply and know the difficulties for them by calculating a specific system, which can take more time and effort for the teacher (Hayek, 2018).

3. Automating basic activities in education: due to the large burden on the teacher when preparing, reviewing and correcting questions, then correcting students' mistakes and evaluating their answers separately. This requires time and effort, which are reduced by implementation of automation systems, and they are performed accurately through artificial intelligence (Hayek, 2018).

4. Supports the student everywhere and at any time: as artificial intelligence devices such as a mobile device equipped with the smart learning method that helps the student to access information at anytime and anywhere and with various educational sources and to find databases for them to facilitate the learning process and fit their educational needs that strengthen the basis of knowledge (Virou.M \& Alepis, E, 2005)

5. Supports teaching smart algebra: The ITS smart algebra system is designed in a way that has many features for artificial intelligence programs to help students learn basic levels of algebra and teach them some equations and symbol processing so that students can use the electronic pencil and the existing commands to help students calculate or input or collect and so on of commands that facilitate algebra operations. Artificial intelligence has proven its success and effectiveness in supporting student learning of algebra (McArthur.D \& Bishay, 2005).

\subsection{Types of Artificial Intelligence}

There are three main types of artificial intelligence, starting from reaction, perception, and self-reaction (Ihab, 2018).

1 - Narrow Artificial Intelligence: This type is one of the simplest types of artificial intelligence. It is programmed to carry out certain functions within a specific environment and only works in its own environment according to the simple reaction. Here it comes in the form of a response.

2 - Strong Artificial Intelligence: This type is characterized by the ability to collect and analyze information, as it accumulates experiences from the situations that it acquires, which qualifies it to make independent and autonomous decisions.

3 - Artificial super intelligence: This type consists of two models under experiment that seek to simulate human beings with two patterns. The first seeks to understand human thoughts and emotions that affect human behavior, while the other type is a model for the theory of the human mind to understand human expressions and predict others' feelings and interact with them and this is the coming generation of Artificial intelligence.

\subsection{Artificial Intelligence Goals}

Among the main goals of artificial intelligence (Al Qasim, 2020):

1- Repetition of human intelligence: as artificial intelligence, with its programs and applications, mimics the human mind.

2- Problem-solving and knowledge-intensive tasks: as artificial intelligence applies its applications in deduction, problem-solving, and decision-making assistance.

3- Making an intelligent connection between technology and action. 
4-Improving interaction Human-to-human contact, person-to-computer, and computer-to-computer.

\subsection{The Importance of Artificial Intelligence}

Artificial intelligence is important since it

1- Facilitates the preservation of human expertise transfer it to smart machines.

2- Enables the human being to use the human language in dealing with machines instead of the computer programming language by virtue of artificial intelligence. Human aspects such as those with special needs can be used.

3- Artificial intelligence plays an important role in sensitive areas such as diagnosing diseases and prescribing drugs, as well as in the military, security and other fields.

4- Artificial intelligence is used extensively in the field of scientific research, which increases scientific growth and development (Abdel Nour, 2004).

\subsection{Artificial Intelligence and Education}

Artificial intelligence is considered one of the best ways to provide assistance to education, as it does not pose any threat to the educational function, but rather it facilitates the tasks and overcomes challenges that teachers face during their education in the traditional methods. It also helps and organizes administrative work in educational institutions and schools, and there are organized databases that are easy to refer to where it is a tremendous achievement and a qualitative change in all fields and aspects, especially the educational field where it promotes the educational process to achieve the highest levels of quality in the near future.(Al Subaihi,2020).

\subsection{Artificial Intelligence and Teaching Children}

Children are not isolated from the changes that have occurred in the world. technology has become an important part of their lives, whether their games or learning, and they use their smart devices in all aspects of their lives because it facilitates understanding the tasks they face.

Many studies have been conducted on the effectiveness of using technology in the lives of children (kindergarten and elementary stage) and that the programs and systems that have been designed for the educational process, including what is in the form of educational games that develop certain skills among children with an element of suspense so they remain interested in the learning process. The result of these studies show that artificial intelligence increases children's motivation during their learning and thus increases their educational attainment, and artificial intelligence programs have facilitated the process of children's education (such as understanding arithmetic operations perfectly) and explaining everything that is difficult for them (Awais, 2019).

\section{Previous Studies}

\subsection{Artificial Intelligence and Children's Education}

Many studies that shed light on artificial intelligence and its relationship to the field of education have been conducted, including:

1-Al-Omari, (2019) conducted a study entitled the effect of using a chat robot for artificial intelligence to develop the cognitive aspects of science for basic stage school female students, and this study aimed to know the effect of artificial intelligence by using the chat robot on the experimental group of sixth-grade students in science subject to develop cognitive aspects in Jeddah in the Kingdom of Saudi Arabia. The results revealed that there are statistically significant differences in favor of the experimental group in the post application of the test compared to the control group, meaning that there is a positive effect of using the chat bot as a type of artificial intelligence in developing the cognitive aspect.

2- Al-Hujaili study (2020) entitled Artificial Intelligence in the Kingdom of Saudi Arabia aimed to know the aspirations of the Kingdom of Saudi Arabia regarding the impact of artificial intelligence on all its institutions and all its fields, including the education sector as an integral part of the Kingdom's vision (2030) and shed light on what can be provided for education and what are the applications and systems that teachers can use? The results showed that artificial intelligence will have a greater role in making education outcomes better, and it will be linked to the labor market.

3-Terah,(2019) conducted a study entitled Requirements for the Introduction of Artificial Intelligence Technology in Egyptian Pre-University Education. This study aimed to highlight what artificial intelligence is, its types and how to introduce it into the pre-university education system. The results indicated that there is necessity to train teachers how 
to apply and use artificial intelligence as part of the education process to keep abreast of technological developments in artificial intelligence with its various applications.

4- Sabaa (2018) study entitled: Application of Artificial Intelligence Strategies at the International Level: The United Arab Emirates as a Model and aimed to find out how to use the Control Application in Artificial Intelligence Strategies to implement in all medical, educational, economic fields as well as in financial markets and so on.

The UAE has adopted artificial intelligence strategies and employed them in all aspects as part of their work mechanism, and the results of using these strategies have been proven to have a positive impact at the level of the state and individuals and achieve economic growth.

5. Abdul-Latif, (2020) conducted a study titled : the effectiveness of an artificial intelligence-based teaching system to develop a profound understanding of nuclear interactions and self-learning capacity among high school students. This study aimed to know the effectiveness of an artificial intelligence-based teaching system that seeks to develop a profound understanding of nuclear interactions and aptitude for self-learning for high school students. A system based on artificial intelligence was prepared to teach the nuclear chemistry unit as well as self-learning scale, and test preparation. Then the system was applied to the experimental group. As for the control group, it remained on the traditional method, and the result was that there were statistically significant differences between the mean scores of the experimental and control group for the posttest in favor of the experimental group and this indicates the effectiveness of the system.

6- Al-Hawamdeh, (2020) conducted a study entitled: Are children intelligent by nature or because of the technology they use. The descriptive and analytical approach was used in this study, which aimed to highlight the effect of technology on intelligence and cognitive development in children and analyze their behavior when using advanced smart devices and whether there is an effect of these devices with its artificial intelligence on their mental abilities, the results indicated that when children, use smart devices a lot, their mental capabilities in solving complex problems reduce and this makes them less intelligent than their peers. This study recommended the restricted use of devices purposefully to preserve their minds.

7- Al-Yajzi, (2019) conducted a study entitled the use of artificial intelligence applications in support university education in the Kingdom of Saudi Arabia. The researcher used the descriptive and analytical approach. The study aimed to know the applications of artificial intelligence that support education in the Kingdom of Saudi Arabia and the results were that these applications support university education and help determine the skills needed for the labor market according to the Kingdom's vision (2030), and these applications take into account the individual differences between learners and work on developing their own learning. It also recommended developing the educational environment to interact with artificial intelligence with its various applications.

8- Owais, (2019) conducted a study entitled: Children's Use of Digital Devices, a field study that aimed to know the pros and cons of using digital devices for basic stage students. It was conducted on children in Egypt by surveying the opinion of teachers, parents and educationalists. It also sought to know the common use of smart programs and applications. The results were that these devices should be used within specific and targeted controls.

9- Al-Subaihi, (2020) conducted a descriptive study entitled Artificial Intelligence in Higher Education in the Kingdom in Saudi Arabia, where this study aimed to know the role of artificial intelligence in educational curricula and how to keep pace with the developments of technological development, the results confirmed the necessity of building the curriculum in a way that includes artificial intelligence in its programs as well as teacher training to use artificial intelligence in the education process.

10. Abdel-Gawad, (2019) conducted a study entitled the effect of the feedback pattern provided through an artificial intelligence-based program on developing programming skills among third-grade students of the second cycle of basic education, where the aim of this study is to identify the patterns of feedback for a specific error through a program based on artificial intelligence in developing the cognitive and performance side of basic programming skills for third-grade students of the second cycle of basic education in Fayoum Governorate, the results were in favor of the experimental group that studied programming skills using the artificial intelligence-based program.

11. Al-Mutairi, (2019) conducted a study entitled Artificial Intelligence as an introduction to the development of educational decision-making in the Ministry of Education in Kuwait, where the study aimed to know the extent to which the Ministry of Education applies artificial intelligence programs in the decision-making process. The research used descriptive approach on a sample of education leaders. The results showed that there is an absence of using artificial intelligence programs and a lack of training for those involved in making decisions, as it was found that there 
is weakness in the criteria for selecting employees, and there is no adoption of artificial intelligence as one of the criteria and the lack of a smart database that facilitates work.

12. Zarrouqi, (2020) conducted a study entitled the role of artificial intelligence in improving the quality of higher education and aimed at knowing the role of artificial intelligence programs in improving education in universities, and the results proved the effectiveness of artificial intelligence programs in that they increase the opportunities for self-learning among students, as these programs are characterized by flexibility, modernity and accuracy. It supports students to gain innovation and creativity during the learning process and increases the process of communication and communication between the teacher and the student, as it facilitated the process of helping the teacher to their students at any time and with the least effort.

13. Al Bado, (2017) conducted a study entitled Smart Learning and its relationship to creative thinking and its most used tools by mathematics teachers in smart learning schools. This study aimed to know the effect of smart learning on creative thinking in mathematics and the results proved that there is a positive relationship between arithmetic means in favor of smart learning by activating smart learning for further improvement in the educational process.

14. Mahmoud, (2020) conducted a study entitled Artificial Intelligence Applications, an introduction to the development of education in light of the challenges of the Corona virus epidemic. It aimed at knowing the applications of artificial intelligence that can be used in the educational process during the Corona pandemic. The descriptive approach was used in the study with regard to analysis and research. Quasi-experimental was also used because there is a questionnaire prepared as a study tool. This open questionnaire was designed to find out the most important challenges and the role of artificial intelligence to overcome them. The results of the study were that artificial intelligence applications should be used as an effective virtual learning system.

15. Mahmoud, (2020) conducted a study entitled the effect of the interaction of some artificial intelligence systems and the academic level on self-awareness and quality of life among a sample of 16-17 year old students. The study aimed to know the effect of the interaction of some artificial intelligence systems and the school level on a sample of 16- 17 years where the self-awareness and quality of life measure was used on the sample of first-secondary students as well as a smart board. The results were in favor of the experimental sample, which means that there is an effect of artificial intelligence systems.

16. Baker, (2018) implemented a paper to speculate on the near future of research in Artificial Intelligence and Education (AIED), on the basis of three uses of models of educational processes: models as scientific tools, models as components of educational artifacts, and models as bases for design of educational artifacts. In terms of the first role, he claims that the recent shift towards studying collaborative learning situations needs to be accompanied by an evolution of the types of theories and models that are used, beyond computational models of individual cognition. In terms of the second role, he proposes that in order to integrate computer-based learning system sin to schools, we need to 'open up' the curriculum to educational technology, 'open up' educational technologies to actors in educational systems and 'open up' those actors to the technology (i.e. by training them). In terms of the third role, he proposes that models can be bases for design of educational technologies by providing design methodologies and system components, or by constraining the range of tools that are available for learners. In conclusion he proposes that a defining characteristic of AIED research is that it is, or should be, concerned with all three roles of models, to a greater or lesser extent in each case.

17. Chen, (2020) conducted a study to assess the impact of Artificial Intelligence (AI) on education, premised on a narrative and framework for assessing (AI) identified from a preliminary analysis. The scope of the study was limited to the application and effects of (AI) in administration, instruction, and learning. A qualitative research approach, leveraging the use of literature review as a research design and approach was used and effectively facilitated the realization of the study purpose. Artificial intelligence is a field of study and the resulting innovations and developments that have culminated in computers, machines, and other artifacts having human - like intelligence characterized by cognitive abilities, learning, adaptability, and decision- making capabilities. The study ascertained that (AI) has extensively been adopted and used in education, particularly by education institution, in different forms. (AI) initially took the form of computer and computer related technologies, transitioning to web-based and online intelligent education systems and ultimately with the use of embedded computer system, together with other technologies, the use of humanoid robots and web-based chat bots to perform instructors duties and function independently or with instructors. Using these platforms, instruction have been able to perform different administrative functions, such as reviewing and grading students assignments more effectively and efficiently,and achieve higher quality in their teaching activities. On the other hand, because the systems leverage machine learning and adaptability, curriculum and 
content has been customized and personalized in line with students needs which has fostered uptake and retention , thereby improving learners experience and overall quality of learning .

18. Tuomi, (2018) conducted a study to assess the impact of artificial intelligence on learning, teaching, and education. This report describes the current state of the art in artificial intelligence (AI) it provides conceptual foundation for wellinformed policy -oriented work, research, and forward -looking activities that address the opportunities and challenges created by resent developments for (AI). The repot is aimed for policy developers, but it also makes contribution that are of interest for (AI) technology developers and researchers studying the impact of (AI) on economy, society, and the future of education and learning.

19. Chassignol, (2018). The purpose of this study was to Digital technologies have already become an internal part of our life. They change the way we are looking for information, how we communicate with each other, even how we behave. This transformation applies to many areas, including education. The main objective of this article is to identify prospective impact of artificial technologies to the study process and to predict possible changes in educational landscape. In presented literature review we considered four categories: customized educational content, innovative teaching methods. Technology enhanced assessment, communication between student and lecturer. Having reviewed publications on the subject we present here a possible picture of how the Artificial Intelligence (AI) will reshape education landscape.

20. Williams, (2020). The purpose of this Pop Bots is a hands-on toolkit and curriculum designed to help young children learn about artificial intelligence (AI) by building, programming, training, and interacting with asocial robot. Today's children encounter AI in the forms of smart toys and computationally curetted educational and entertainment content. However, children have not yet been empowered to understand or create with this technology. Existing computational thinking platforms have made ideas like sequencing and conditionals accessible to young learners. Going beyond this, we seek to make AI concepts accessible. We designed Pop Bots to address the specific learning needs of children age's four to seven by adapting constructionist ideas into an AI curriculum. This paper describes how we designed the curriculum and evaluated its effectiveness with 80 PreK and Kindergarten children. We found that the use of a social robot as a learning companion and programmable artifact was effective in helping young children grasp AI concepts. We also identified teaching approaches that had the greatest impact on student's learning. Based on these, we make recommendations for future modules and iterations for the Pop Bots platform. Children growing up in the era of artificial intelligence (AI) will have fundamentally different relationships with smart technologies than those who first encountered Eater in life. New AI-enabled interfaces that support inter-action through gesture, touch, and speech allow younger and younger children to access digital content and services. However, young children do not yet understand how AI-enabled devices, such as smart toys, work. It is important that they do, however, so that children can use them constructively and safely. Although there are a growing number of resources to learn about AI, most of these curricula target students in high school or beyond, and very few are appropriate for non-programmers. For this reason, we designed a nearly AI curriculum to help young children learn about artificial intelligence by enabling them to build, program, train and interact with their own social robots. The Pop Bots Platform and Curriculum consists of a social robot toolkit, three hands-on AI activities, and associated assessments for young children to explore machine learning reasoning, and generative algorithms. In this paper, we discuss the tools we developed and the results of an evaluative study with 80 four-to-six year olds. We investigated differences in how well children understood AI concepts based on age and gender as well as children's hands on interaction with the Pop Bots toolkit components. While factors like prior technical skills and age can certainly impact how much children can learn, we hypothesized that their interaction with the toolkit would really drive their understanding.

21. (Jaakkola, 2020). Artificial Intelligence (AI) is one of the emerging technologies of today. It provides applications in addition to the traditional computing environments, and is also in affordable smart devices, making AI available everywhere. These affordable devices have built-in capabilities to handle complex computing tasks (edge computing), flexible access to fast network resources, access to cloud-based services to solve complex problems on a collaborative basis, and access to an enormous amount of open and closed data resources. In education, AI contributes in at least two ways: (1) the scope and content of education - what kind of education is needed; and (2) the process of education support and changes to education and the teacher's work. In the scope of education, we must consider that AI (and related technologies) will replace some jobs (education will no longer be needed), some jobs will change dramatically (education content must be modified), and a lot of new jobs will be generated (new education must be established). In the process of education - the work itself - AI will have and has the role of reformer and enabler, which also changes the characteristics and division of duties. In this paper we analyze the opportunities and challenges caused by AI in education. Although the focus is on the role of AI, it is difficult to separate it from other technology-driven changes, especially in the discussion about work life. 
22. (Reddy, 2020). The Industry 4.0 has affected not only various industrial sectors, business, governance and the people, but also education leading to Education 4.0. One of the unique characteristics of industry 4.0 and Education 4.0 is the application of Artificial Intelligence (AI). Personalization of E-learning systems is dominating Education 4.0 as learners have varying ambitions, background, skills, intelligence and unique personalities. Education 4.0 is primarily shaped by AI, which include AI based learning portal supporting teachers' efforts, adaptive content delivery, integration of certified resources with personalized learning on real time basis, greater institutional offering of AI driven e-learning and E-tools on web pages. The key applications of AI in Education include automation of routine activities, customizable smart content, immersive learning, and identification of drivers of enhancing students' performance, early warning signs of dropouts, personalized learning, learning analytics, adaptive learning, intelligent chat bots and predictive modeling. Personalized Adaptive Learning (PAL) is amalgamation of personalized learning and adaptive learning. Personalized learning involves adapting of curriculum, learning and pedagogy to measure up to customized needs to meet the needs and goals of learners. Adaptive learning denotes the technologies tracking the learners progress, using data to amend learning path dynamically. An exploratory study based on the secondary resources has been undertaken in this research paper wherein Industry 4.0, Education 4.0, components of PAL, various AI techniques, challenges and approaches to adopting AI in Education 4.0 are reviewed and analyzed.

23. (Brummele, 2020). With children talking to smart-speakers, smart-phones and even smart-microwaves daily, it is increasingly important to educate students on how these agents work-from underlying mechanisms to societal implications. Researchers are developing tools and curriculum to teach K-12 students broadly about artificial intelligence (AI); however, few studies have evaluated these tools with respect to AI-specific learning out-comes, and even fewer have addressed student learning about AI-based conversational agents. We evaluate our Conversational Agent Interface for MIT App Inventor and workshop curriculum with respect to 8 AI competencies from the literature. Furthermore, we analyze teacher $(n=9)$ and student $(n=47)$ feedback from workshops with the interface and recommend that future work leverages design considerations from the literature to optimize engagement, collaborates with teachers, and addresses a range of student abilities through pacing and opportunities for extension. We found students struggled most with the concepts of AI ethics and learning, and recommend emphasizing these topics when teaching.

24. (Kulikov, 2020). Sequential transformative design of research (Hanson et al. in J Counts Psycho 52(2):224-235, 2015; Groleauet al. in J Mental Health 16(6):731-741, 2007; Robson and McCarran in Real world research: a resource for users of social research methods in applied settings, Wiley, Chic ester, 2016) allows testing a group of theoretical assumptions about the connections of artificial intelligence with culture and education. In the course of research, semiotics ensures the description of self-organizing systems of cultural signs and symbols in terms of artificial intelligence as a special set of algorithms. This approach helps to consider the arguments proposed by Searle (Behav Brain Sci 3(3):417-457, 1980) against 'strong' artificial intelligence. Searle (Behav Brain Sci 3(3):417-457, 1980) believes that artificial or machine intelligence cannot fully emulate the processes of the human mind. Machine intelligence shows own inevitable weakness. This is non-autonomous tool for computations and data operating. In fact, this tool cannot provide insight into real cognitive conditions. After Lot man and Uspensky (On the semiotics mechanism of culture, Alexandra, Tallinn, 1993), authors expand the meaning of artificial intelligence. The authors identify a cultural type of 'strong' artificial intelligence or 'self-increase of Logos' in terms by Lot man and Uspensky (On the semiotics mechanism of culture, Alexandra, Tallinn, 1993). The interpretation of human intelligence as imitation of machine intelligence makes possible such immersion of artificial intelligence in culture. The authors reveal a case of self-organizing autonomous generation, encoding, decoding, reception, storage, and transmission of social information in the field of physical training. From the empirical studies it is clear that the organization of collective activities without external control ensures the development of positive emotions and social orientations. Interest in autonomous behavior provides the formation of educational and cognitive motives. As a special set of algorithms, these motives are the most promising and favorable for personal development.

25. (Zmyzgova, 2020).The problem of digital transformation of the education system in the Russian Federation is considered. The problems connected with the use of artificial intelligence technologies to create a fundamentally new quality education system are discussed. The problem of digital transformation of education, features of introduction of technologies of an artificial intellect in a modern reality is stated. The concept of electronic adaptive learning, in particular, adaptive intellectual learning platforms, is considered. The basic trends in modern electronic education, which make possible realization of adaptive electronic learning in the digital environment, are briefly listed. It is shown that the adaptive digital environment is the center of formation of value professional competences and attitudes of the learner. The specifics of using artificial intelligence to ensure inclusion and equality in education are presented. The 
prospects of using artificial intelligence in the Russian Federation on the basis of the developed National Strategy of Artificial Intelligence Development till 2030 are considered.

\subsection{Comments and Feedback on the Previous Studies}

As far as the effective role of artificial intelligence applications are concerned, the previous studies are similar in that they help students to improve their education process. These applications facilitate education methods with a minimum of time and effort. They can receive education in every place and time. These studies also showed the role of artificial intelligence in helping teachers to overcome the challenges and difficulties that may face them in the education process. These applications helped them to organize their records and have organized databases. The role of artificial intelligence in the education system in general helps in the progress and prosperity of countries; so all recommendations were made to pay attention to artificial intelligence activation in the educational system in general.

The four studies mentioned above seek to address the impact of artificial intelligence (AI) on education. They emphasize the necessity of integration artificial intelligence with the traditional teaching process. This integration requires the fulfillment of certain conditions or circumstances such as curriculum adaptation, training of all the parties involved.

\subsection{Summary of AI Studies}

Table 1 shows a summary of 25 studies about AI in the World and the Arab World and Saudi Arabia.

Table 1. A summary of 25 studies about AI

\begin{tabular}{|c|c|c|c|c|}
\hline No & Title & $\begin{array}{c}\text { Year of } \\
\text { publication }\end{array}$ & Author & $\begin{array}{l}\text { Country of the } \\
\text { study }\end{array}$ \\
\hline 1 & $\begin{array}{l}\text { The effect of chat robot of the artificial intelligence on } \\
\text { the development of cognitive aspects in science among } \\
\text { basic stage female students }\end{array}$ & 2019 & $\begin{array}{l}\text { Zuhoor Hassan } \\
\text { Alomari }\end{array}$ & $\begin{array}{l}\text { Saudi Arabia } \\
\text { Jeddah }\end{array}$ \\
\hline 2 & Artificial intelligence in Saudi Arabia & 2020 & $\begin{array}{l}\text { Samar Ahmad } \\
\text { Suliman } \\
\text { Alhujaili }\end{array}$ & Saudi Arabia \\
\hline 3 & $\begin{array}{l}\text { Requirements for introducing artificial intelligence } \\
\text { technology into Egyptian pre-university education }\end{array}$ & 2019 & $\begin{array}{l}\text { Mariam Shawqi } \\
\text { Abdulrahman } \\
\text { Tarah }\end{array}$ & Egypt \\
\hline 4 & $\begin{array}{l}\text { The application of artificial intelligence strategies at the } \\
\text { international level: the United Arab Emirates as a } \\
\text { model }\end{array}$ & 2018 & $\begin{array}{l}\text { Ahmad Saleh } \\
\text { Saba }\end{array}$ & $\begin{array}{l}\text { United Arab } \\
\text { Emirates }\end{array}$ \\
\hline 5 & $\begin{array}{l}\text { The effectiveness of an artificial intelligence-based } \\
\text { teaching system to develop a deep understanding of } \\
\text { nuclear interactions and self-learning capacity for high } \\
\text { school students }\end{array}$ & 2020 & $\begin{array}{l}\text { Osama Jibril } \\
\text { Ahamad } \\
\text { Abdullateef }\end{array}$ & Egypt \\
\hline 6 & Are children innately intelligent or technologically? & 2020 & $\begin{array}{l}\text { Mukhled Ulaian } \\
\text { Alhawamdeh }\end{array}$ & Jordan \\
\hline 7 & $\begin{array}{l}\text { The use of artificial intelligence applications to support } \\
\text { university education in Saudi arabia }\end{array}$ & 2019 & Faten $\quad$ Yajoz & Saudi Arabia \\
\hline 8 & Children use of digital appliances & 2019 & $\begin{array}{l}\text { Afaf Ahmad } \\
\text { Owais }\end{array}$ & Egypt \\
\hline 9 & $\begin{array}{l}\text { Artificial intelligence in higher education in Saudi } \\
\text { Arabia }\end{array}$ & 2020 & $\begin{array}{l}\text { Noor Abdelaziz } \\
\text { Alsubaihi }\end{array}$ & Saudi Arabia \\
\hline 10 & $\begin{array}{l}\text { The effect of feedback type introduced through artificial } \\
\text { intelligence- based program on the development of } \\
\text { programming skills among third grade students - second }\end{array}$ & 2019 & $\begin{array}{l}\text { Saied Nooh } \\
\text { Saied }\end{array}$ & Egypt \\
\hline
\end{tabular}




\begin{tabular}{|c|c|c|c|c|}
\hline & course of basic education & & Abdeljawad & \\
\hline 11 & $\begin{array}{l}\text { Artificial intelligence as an introduction to decision } \\
\text { making improvement in the ministry of education in } \\
\text { Kuwait }\end{array}$ & 2019 & $\begin{array}{l}\text { Adel Mijbil } \\
\text { Almutairi }\end{array}$ & Kuwait \\
\hline 12 & $\begin{array}{l}\text { The role of artificial intelligence in the improvement of } \\
\text { the higher education }\end{array}$ & 2020 & Riad Zarooqi & Algeria \\
\hline 13 & $\begin{array}{l}\text { Smart learning and its relationship with creative } \\
\text { thinking and its tools most used by mathematics } \\
\text { teachers in smart learning schools }\end{array}$ & 2017 & $\begin{array}{l}\text { Amal } \\
\text { Mohammed } \\
\text { Albado }\end{array}$ & Palestine \\
\hline 14 & $\begin{array}{l}\text { Artificial intelligence applications as an introduction to } \\
\text { the development of education in the light of Corona } \\
\text { virus epidemic challenges }\end{array}$ & 2020 & $\begin{array}{l}\text { Abdulrazaq } \\
\text { Mukhtar } \\
\text { Mahmoud }\end{array}$ & Egypt \\
\hline 15 & $\begin{array}{l}\text { The impact of the interaction of some artificial } \\
\text { intelligence systems and the school level on } \\
\text { self-awareness and quality of life among a sample of } \\
\text { students aged } 16-17 \text { years }\end{array}$ & 2020 & $\begin{array}{l}\text { Eman } \\
\text { Abdulwahab } \\
\text { Mahmoud }\end{array}$ & Saudi Arabia \\
\hline 16 & $\begin{array}{l}\text { The roles of models in Artificial Intelligence and } \\
\text { Education research: a prospective view }\end{array}$ & 2018 & Michael J. Baker & $\begin{array}{l}\text { Université } \\
\text { Lumière Lyon }\end{array}$ \\
\hline 17 & Artificial Intelligence in Education: A Review & 2020 & $\begin{array}{l}\text { L CHEN, P } \\
\text { CHEN, Z LIN }\end{array}$ & China \\
\hline 18 & $\begin{array}{l}\text { The Impact of Artificial Intelligence on Learning, } \\
\text { Teaching, and Education. }\end{array}$ & 2018 & Tuomi, Ilkka & Luxembourg \\
\hline 19 & $\begin{array}{l}\text { Artificial Intelligence trends in education: a narrative } \\
\text { overview. }\end{array}$ & 2018 & $\begin{array}{l}\text { M Chassignol, A } \\
\text { and K, A } \\
\text { Klimova and A } \\
\text { Bilyatdinova }\end{array}$ & Russia \\
\hline 20 & $\begin{array}{l}\text { Pop Bots : Designing an Artificial Intelligence } \\
\text { Curriculum for Early Childhood Education. }\end{array}$ & 2020 & $\begin{array}{l}\text { R Williams, HW } \\
\text { Park, L Oh ,C } \\
\text { Breazeal }\end{array}$ & Massachusetts \\
\hline 21 & Artificial Intelligence and Education & 2020 & $\begin{array}{l}\text { H. Jaakkola, J. } \\
\text { Henno, A. Lahti, } \\
\text { J. -P. Järvinen } \\
\text { and J. }\end{array}$ & Croatia \\
\hline 22 & $\begin{array}{l}\text { Analysis of Artificial Intelligence Based Personalised } \\
\text { Adaptive Learning(PAL) In Education }\end{array}$ & 2020 & $\begin{array}{l}\text { R Reddy, M } \\
\text { Tiwari, Dr R } \\
\text { Chavan }\end{array}$ & Mumbai \\
\hline 23 & $\begin{array}{l}\text { Teaching Tech to Talk: K-12 Conversational Artificial } \\
\text { Intelligence Literacy Curriculum and Development } \\
\text { Tools }\end{array}$ & 2020 & $\begin{array}{l}\text { J Brummelen, T } \\
\text { Heng, V } \\
\text { Tabunshchyk }\end{array}$ & $\begin{array}{l}\text { (Massachusett) } \\
\text { United States }\end{array}$ \\
\hline 24 & Artificial Intelligence, Culture and Education & 2020 & $\begin{array}{l}\text { Kulikov, S.B., } \\
\text { Shirokova, A.V. }\end{array}$ & Tomsk, Russia \\
\hline 25 & $\begin{array}{l}\text { Digital Transformation of Education and Artificial } \\
\text { Intelligence }\end{array}$ & 2020 & $\begin{array}{l}\text { Zmyzgova } \\
\text { T.R.PolyakovaE. } \\
\text { N.Karpov E.K. }\end{array}$ & Russia \\
\hline
\end{tabular}




\section{References}

Abdel Nour, A. (2004). Introduction to artificial intelligence. Riyadh. Al-Faisal Cultural House.

Abdul-Jawad, S. N. (2019). The effect of the feedback pattern provided through an artificial intelligence-based program on developing programming skills among third-grade students from the second cycle of basic education. Fayoum University Journal of Educational and Psychological Sciences, (12), 179-219.

Abdullatif, O. J. (2020). The effectiveness of an artificial intelligence-based teaching system to develop a profound understanding of nuclear interactions and a capacity for self-learning among secondary school students. Journal of Scientific Research in Education, (21), 307-349.

Al Hilah, M. M. (2014). Education technology between theory and application. Al Masirah House for Publishing and Distribution. Amman.

$\mathrm{Al}$ Qasim, F. (2020). Introduction to artificial intelligence. Riyadh. Al-Faisal Cultural House.

Albado, A. M. (2017). Smart learning and its relationship with creative thinking and its most used tools by mathematics teachers in smart learning schools. Journal of Islamic Sciences for Educational and Psychological Studies, (2).

Al-Mutairi, A. M. (2019). Artificial Intelligence as an introduction to the development of educational decision-making in the Ministry of Education in of Kuwait. Journal of Scientific Research in Education, (20), 573-588.

Al-Subaihi, N. A. A. (2020). Artificial intelligence in higher education in the Kingdom of Saudi Arabia. Arab Journal of Educational and Psychological Sciences, (17), 103-116.

Al-Yajouzi, F. (2019). Using artificial intelligence applications to support university education in the Kingdom of Saudi Arabia. Arab Studies in Education and Psychology, (113), 275-282.

Brummelen, J., Heng, T., \& Tabunshchyk, V. (2020). Teaching Tech to Talk: K-12 Conversational Artificial Intelligence Literacy Curriculum and Development Tools. Massachusetts Institute of Technology Cambridge. Journal of Educational and Psychological Sciences, 38-45.

Hassan, Z. (2019). The effect of using an artificial intelligence chat bot to develop the cognitive aspects of science for elementary schoolfemale students. Saudi Journal of Educational Sciences, (64), 23-48.

Hawamdeh, M. A. (2020). Are children intelligent by nature or because of the technology they use. Journal of Educational and Psychological Sciences, 145-160.

Hayek, H. (2018). The roles of artificial intelligence will change the future of education. Naseej Academy.

Ihab, K. (2018). Artificial intelligence opportunities and threats in the next ten years. Al-Ahdath Magazine, (27).

Jaakkola, H., Henno, J., Lahti, A., Järvinen, J.-P., \& Mäkelä, J. (2020). Artificial Intelligence and Education. 2020 43rd International Convention on Information, Communication and Electronic Technology (MIPRO), Opatija, Croatia, pp. 548-555. https://doi.org/10.23919/MIPRO48935.2020.9245329

Kulikov, S. B., \& Shirokova, A.V. (2020). Artificial intelligence, culture and education. AI \& Soc. https://doi.org/10.1007/s00146-020-01026-7

Mahmoud, A. R. M. (2020). Artificial intelligence applications as an entry to the development of education in light of the challenges of the Corona virus epidemic. International Journal of Research in Educational Sciences, (4), 171-224. https://doi.org/10.29009/ijres.3.4.4

Mahmoud, I. A. W. (2020). The effect of the interaction of some artificial intelligence systems and the school level on self-awareness and quality of life among a sample of students aged 16-17 years. Arab Studies in Education and Psychology, (119), 259-298.

Makkawi, M. A.-R. (2018). Artificial Intelligence at the Doors of Education. The Caravan Magazine, (6), 22-25.

Naseeb, S. (2020). Artificial Intelligence and its Future Implications for Humans. Retrieved from https://www.arabthought.org/ar/researchcenter/ofoqelectronic-article details

Owais, A. A. (2019). Children use of digital devices. Childhood and Development Journal, 34-38.

Qamoura, S. (2018). Artificial Intelligence between Reality and Expectation: Artificial Intelligence Forum, a Challenge to Artificial Intelligence. 
Reddy, R., Tiwari, M., \& Chavan, R. (2020). Analysis of Artificial Intelligence Based Personalised Adaptive Learning (PAL) InEducation 4.0: An Exploratory Study, pp. 123-133.

Sabaa, A. S. (2018). The application of artificial intelligence strategies at the international level: the United Arab Emirates as a model. Economic Fields Magazine, (1), 31-43.

Sherida, S. M. (2020). The effectiveness of the program based on activating activity hours to develop some life skills for early childhood children. The Arab Journal of Information and Child Culture, (12), 153-172.

Tara, M. S. A. A.-R. (2019). Requirements for the introduction of artificial intelligence technology in Egyptian pre-university education. Algerian Journal of Human Studies, (2), 372-349.

Zmyzgova, T. R., Polyakova, E. N., \& Karpov, E. K. (2020). Digital Transformation of Education and Artificial Intelligence. Advances in Economics, Business and Management Research, 138, 824-829.

\section{Copyrights}

Copyright for this article is retained by the author(s), with first publication rights granted to the journal.

This is an open-access article distributed under the terms and conditions of the Creative Commons Attribution license (http://creativecommons.org/licenses/by/4.0/). 